\title{
Whipple's disease revisited
}

\author{
S A Misbah, N P Mapstone
}

\begin{abstract}
Whipple's disease has traditionally been considered to be a rare multisystem disorder dominated by malabsorption. The recent identification of the Whipple's disease bacillus has, using polymerase chain reaction based assays, fuelled advances in the investigation, diagnosis, and management of this disease. This leader reviews the aetiology, clinical manifestations, investigation, and treatment of Whipple's disease in the light of this new information.

(F Clin Pathol 2000;53:750-755)
\end{abstract}

Keywords: Tropheryma whippelii; immune system; polymerase chain reaction

Whipple's disease, as described by George Whipple in 1907, a pathologist at John's Hopkins Hospital, has generally been considered to be a rare multisystem disorder dominated by malabsorption. Whipple's original patient presented with severe malabsorption associated with mesenteric lymph node enlargement, arthritis, and skin pigmentation. At necropsy, Whipple presciently observed the presence of foamy macrophages and large numbers of argyrophilic rod shaped structures in the lymph nodes. ${ }^{1}$ These foamy macrophages were later shown to stain strongly with the periodic acid

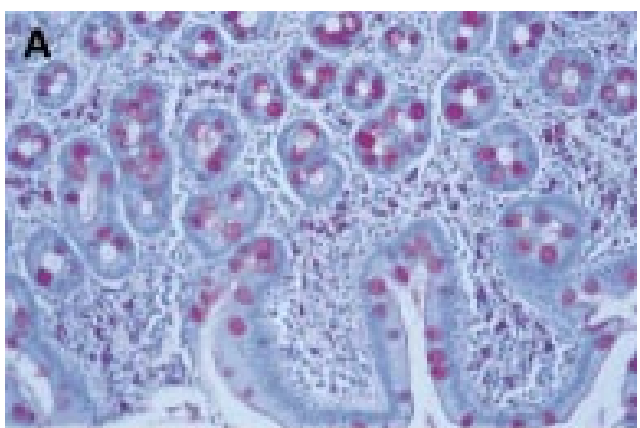

Yorkshire Regional Immunology Service and Molecular Pathology, The Leeds Teaching Hospitals Trust, Leeds General Infirmary, Leeds

LS1 3EX, UK

S A Misbah N P Mapstone

Correspondence to: Dr Misbah sirajm@ pathology.leeds.ac.uk

Accepted for publication 28 April 2000

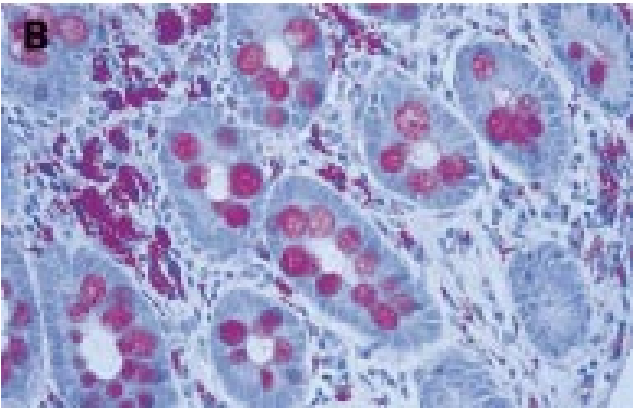

Figure 1 (A) Small bowel of a patient with Whipple's disease showing numerous periodic acid Schiff (PAS) positive macrophages in the lamina propria (magnification, $\times 50)$. (B) Same biopsy at a higher magnification $(\times 100)$ showing macrophages containing PAS positive granules.

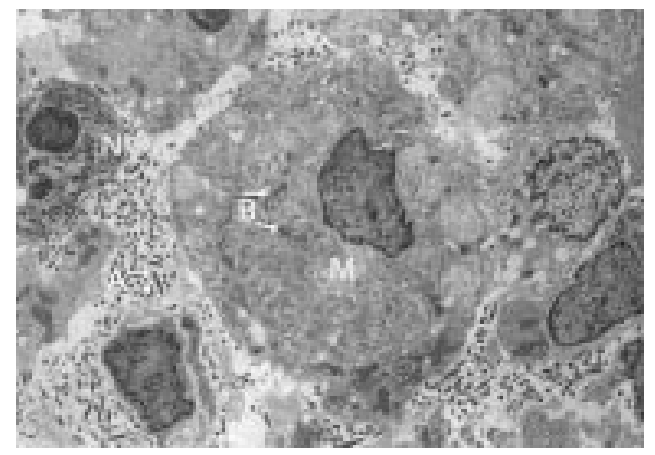

Figure 2 Electron micrograph of small bowel tissue showing numerous extracellular bacilli $(A)$, a phagosome containing bacilli (B) within a macrophage (M), and a neutrophil $(N)$ (reproduced with permission ${ }^{2 a}$ ).

Schiff reagent (PAS) (fig 1), and this soon became accepted as the diagnostic hallmark of Whipple's disease. The infective aetiology of this disorder was first proposed in 1952 when a patient with Whipple's disease, hitherto uniformly fatal, responded to antibiotic treatment. ${ }^{2}$ Further support for an infective aetiology arose from the use of electron microscopy to demonstrate that the foamy macrophages in Whipple's disease were packed with bacillary structures (fig 2), ${ }^{3}$ hereafter referred to as the Whipple's bacillus.

This article will review Whipple's disease and its protean manifestations in the light of recent advances in the aetiology, diagnosis, and management of this enigmatic disease.

\section{Aetiology}

The infective aetiology of Whipple's disease has always been questioned by purists on the grounds that Koch's postulates have not been fulfilled. The limitations of Koch's postulates in relation to unculturable or fastidious microbes that can be identified predominantly by molecular means has been discussed fully by Fredricks and Relman. ${ }^{4}$ The growing body of recent molecular and microbiological evidence strengthening the causative role of the Whipple's bacillus in this disorder is summarised in the ensuing paragraphs.

A major advance in our understanding of Whipple's disease was the identification of the uncultured Whipple's bacillus by two groups using the polymerase chain reaction (PCR)..$^{5}$ Because portions of bacterial 16S ribosomal RNA genes are highly conserved, both groups reasoned that a combination of broad range and specific eubacterial $16 \mathrm{~S}$ ribosomal primers could be used to amplify uncharacterised organisms such as the Whipple's bacillus. Analysis of the 16S ribosomal RNA sequence associated with Whipple's disease suggested that this bacillus was closely related to the actinomycetes group of Gram positive bacteria. 
On the basis of its phylogenetic relations and its tendency to cause malabsorption, Relman and colleagues proposed that the Whipple's bacillus be named Tropheryma whippelit ${ }^{6}$ (from the Greek trophe (nourishment) and eryma (barrier) because it causes malabsorption).

After a succession of false starts, the quest to culture the Whipple's bacillus recently received a major boost when Schoedon et al were able to isolate $T$ whippelii using a novel strategy. ${ }^{7}$ Homogenates of infected heart valves from a patient with systemic Whipple's disease were injected into human mononuclear phagocytes that had been pretreated with interleukin 4 (IL-4), IL-10, and dexamethasone. Within eight to 10 days, diastase resistant, PAS positive inclusions were detected in the mononuclear phagocytes. Subsequent molecular analysis and electron microscopy studies showed that the PAS positive inclusions were $T$ whippelii. If substantiated, this work will be an important advance, which is likely to further our understanding of the immunopathogenesis of Whipple's disease and pave the way for serological assays. ${ }^{8}$

\section{The immune system and Whipple's disease}

There has been much interest in the possibility that patients with Whipple's disease have a primary defect in host defence mechanisms, which render them susceptible to this disorder. Several immunological changes have been demonstrated in patients with Whipple's disease, although it has been difficult to distinguish between primary and secondary effects (fig 3)..$^{9-11}$ Any attempt to implicate a host immune defect in the pathogenesis of Whip-

\section{Humoral immunity}

Total serum Ig levels

Specific antibody responses to infectious agents

Normal in most patients

† Serum $\lg G 2^{\star \star}$

\section{Cellular immunity}

4 Expression of CD45 RO, a marker of memory on T cells

$\uparrow$ Expression of CD25, CD58 on T cells - suggesting T cell activation

$\downarrow$ T cell proliferation to mitogens

Reviewed in reference 54

Impaired delayed type hypersensitivity

$\downarrow$ Expression of CD11b (complement receptor type 3)
By PBMC in vitro $\star$

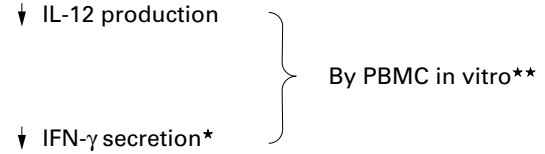

Figure 3 Immunological changes in Whipple's disease. ${ }^{\star}$ See Marth and colleagues ${ }^{12}$; *decreased IFN- $\gamma$ production in vitro is overcome by adding IL-12 to the culture. IFN- $\gamma$, interferon $\gamma ;$ IL-12, interleukin 12; PMBC, peripheral blood mononuclear cells. ple's disease has to take into account the fact that most patients with this disease do not appear to be susceptible to other opportunistic infections. Furthermore, Whipple's disease is not a feature of patients with defective immunity, either cellular or humoral. These clinical observations suggest that any immune defect is likely to be subtle. The idea that such a defect exists has recently been rekindled by evidence of defective in vitro IL-12 and interferon $\gamma($ IFN- $\gamma)$ production by peripheral blood mononuclear cells from patients with Whipple's disease. ${ }^{12} \mathrm{IL}-12$ is a pivotal mediator of cellular immunity, which acts as a trigger for IFN- $\gamma$ production by $\mathrm{T}$ helper type 1 cells. Interestingly, defective cytokine secretion in this study was accompanied by low concentrations of serum IgG2, an IFN- $\gamma$ dependent IgG subclass. Although it is difficult to comment on the clinical relevance of this finding in the absence of data on immunisation responses, it nevertheless provides a thought provoking link with other reports of IgG2 subclass deficiency and granulomatous disease in some patients with Whipple's disease. ${ }^{13}$

\section{Epidemiology}

The rarity of this disease has meant that precise figures on disease prevalence are not available. Dobbins in his meticulous monograph drew attention to 617 cases reported worldwide between 1907 and 1986, and a further 79 unreported cases. ${ }^{14}$ The use of improved diagnostic methods since then suggests that this figure is likely to be a great underestimate. Dobbins also reported a preponderance of farmers and outdoor workers among those afflicted with Whipple's disease. This observation has recently been strengthened by the demonstration of $T$ whippelii in sewage samples. ${ }^{15}$

\section{Clinical manifestations}

Whipple himself described the diverse features of this disease with the exception of neurological involvement. By the time of diagnosis, most $(85 \%)$ patients have diarrhoea on a background of arthralgia, weight loss, lymphadenopathy, fever, and sweats. ${ }^{16}$ The gastrointestinal dominance of symptoms at diagnosis is in direct contrast to the early symptoms of disease, which are predominantly articular. Articular involvement is characterised largely by a migratory, symmetrical non-erosive polyarthritis affecting the knees, ankles, and wrists. ${ }^{17}$ The non-specific nature of these initial articular symptoms is reflected in the considerable delay in the time taken for diagnosis, with average delays of 72 months. ${ }^{16}$ Most case series report an adult male preponderance, with only a few cases presenting in childhood. The rarity of Whipple's disease in childhood despite the tendency of some children to inadvertently eat soil is unexplained.

Neurological involvement occurs in $21-43 \%$ of cases of Whipple's disease. ${ }^{16}{ }^{18} 19$ This may occur either on a background of gastrointestinal symptoms in a patient with known Whipple's disease or present de novo without gastrointestinal involvement. ${ }^{20-22}$ Many neu- 
rologists are familiar with the characteristic triad of dementia, external ophthalmoplegia, and facial myoclonus, which is seen in over a third of patients, ${ }^{14}$ and would consider the possibility of Whipple's disease in such a situation, even in the absence of gastrointestinal involvement. Claims by some neurologists that certain forms of ocular muscle movement abnormalities, such as oculomasticatory myorhythmia, are on their own sufficient to diagnose Whipple's disease ${ }^{23}$ (without supporting histology or PCR analysis) should be viewed with scepticism. Despite the relatively high index of suspicion among neurologists for Whipple's disease, rare patients presenting with pure spinal or muscle involvement pose difficult diagnostic problems. ${ }^{13}$

The presence of systemic granulomatous inflammation in lymph nodes, liver, and spleen in $9 \%$ of patients with Whipple's disease not unreasonably leads clinicians to consider the possibility of sarcoidosis. ${ }^{24-26}$ Over 20 such cases have been documented and illustrate the difficulties in differentiating these two disorders. In some of these cases, raised serum angiotensin converting enzyme concentrations and an increase in gallium 67 uptake on lung scans have also been noted. ${ }^{27}$ The diagnosis of Whipple's disease only becomes apparent in these cases if PAS positivity is demonstrated in tissue biopsies or if gastrointestinal features supervene.

Cardiac involvement in Whipple's disease can affect any layer of the heart. Rare cases of endocarditis have been reported always on a background of intestinal disease. ${ }^{28-31} \mathrm{~A}$ recent report, however, draws attention to four patients with endocarditis caused by $T$ whippelii who presented with cardiac disease de novo with background articular symptoms but with no histological evidence of gastrointestinal disease. ${ }^{32}$ This report underlines the need for Whipple's disease to be considered as a possible cause of culture negative endocarditis. ${ }^{33}$

Ocular involvement has been estimated to occur in $2-3 \%$ of patients with Whipple's disease. ${ }^{34}$ A range of ocular manifestations has been described including anterior and posterior uveitis, vitritis, retinitis, and retrobulbar neuritis. Most cases occur on a background of systemic disease. In those rare cases where ocular disease occurs in the absence of gastrointestinal features, considerable delays in diagnosis ensue. ${ }^{35}$

\section{Investigation of a patient with suspected Whipple's disease}

Given its protean manifestations, the diagnosis of Whipple's disease should be considered in a variety of clinical situations (table 1), irrespective of gastrointestinal involvement. The diagnosis is based upon the demonstration of

Table 1 Clinical situations in which Whipple's disease should be part of the differential diagnosis

Unexplained malabsorption on a background of systemic disease

Unexplained systemic granulomatous disease resembling sarcoidosis

Neurological disease characterised by myoclonus, dementia, and supranuclear ophthalmoplegia

Unexplained culture negative endocarditis

Unexplained uveitis
Table 2 List of organisms that stain positively with the periodic acid Schiff reagent
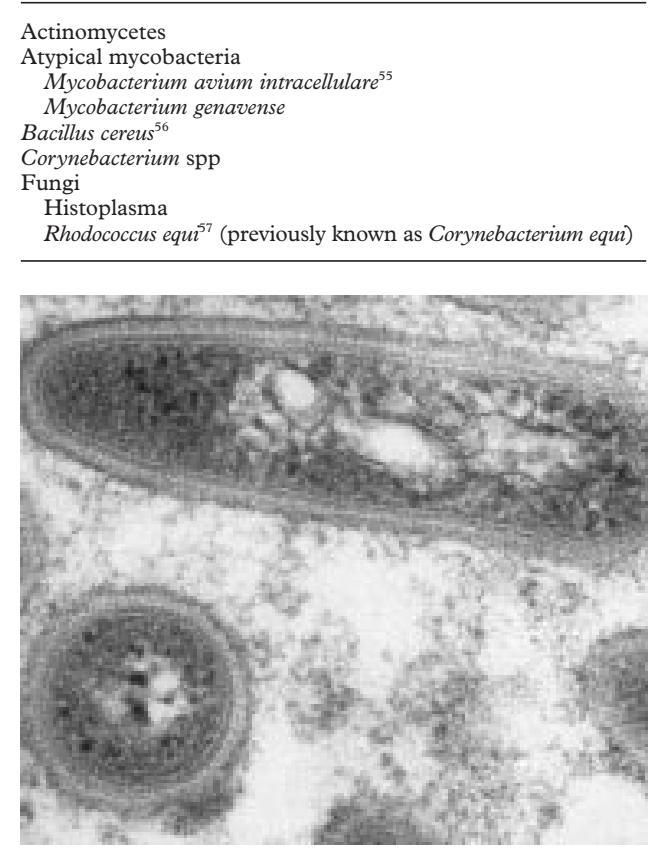

Figure 4 The appearance of the Whipple's bacillus on electron microscopy (magnification, $\times 100$ 000), showing the characteristic trilamellar cell wall (reproduced with permission ${ }^{35 a}$ ).

diastase resistant, PAS positive macrophages on tissue biopsies coupled with PCR evidence of infection with $T$ whippelii. The presence of PAS positive foamy macrophages, which has been considered the traditional hallmark of Whipple's disease, can also occur in other infective disorders that closely mimic Whipple's disease (table 2), thus reducing its specificity. Furthermore, PAS positivity can be patchy or deep in the submucosa, and thus missed on single, superficial biopsies. The electron microscopic demonstration of bacilli with a characteristic trilamellar wall (fig 4) has been considered to be specific for Whipple's disease. However, electron microscopy as a diagnostic tool is heavily operator dependent and being eclipsed in many areas of diagnostic pathology by advances in immunocytochemistry and molecular biology. For this reason, histological evidence of PAS positivity should always be complemented by PCR analysis for $T$ whippelii. Two sets of well characterised primers with differing rates of sensitivity ${ }^{36}(96.6 \%$ for W3AF, W4AR and $59 \%$ for W3FE, W2RB) are currently available for performing PCR analysis. To maximise its sensitivity, PCR analysis should be performed on more than one tissue substrate. Several recent studies suggest that small intestine, even when histologically normal, yields the highest proportion of positive results followed by other tissues such as lymph node, bone marrow, muscle, synovium, and spinal cord. ${ }^{36}$ PCR positivity in peripheral blood and cerebrospinal fluid (CSF) occurs in approximately $50-80 \%$ of samples, respectively, and is a useful method of monitoring response to treatment. ${ }^{3839}$ Interestingly, positive PCR results in CSF were reported in seven of 10 patients without neurological 
symptoms before the initiation of antibiotic treatment. ${ }^{38}$ This finding underlines the need for the use of antimicrobials with good CSF penetration in the treatment of Whipple's disease (see below).

\section{Interpretation of PCR results}

The increasing use of PCR for detecting $T$ whippelii has uncovered several PCR positive patients with systemic disease with or without gastrointestinal involvement in the absence of PAS positivity who respond to prolonged antibiotic treatment. ${ }^{13} 40-42$ These patients had a variety of presentations including diarrhoea, polyarthritis, culture negative endocarditis, and atypical progressive supranuclear palsy. Although this observation calls into question the reliance on PAS positivity as a diagnostic marker for Whipple's disease, recent studies suggest caution in using positive PCR results alone to make a definitive diagnosis. Ehrbar et al found recently that five of 105 patients $(4.8 \%)$ with no clinical signs of Whipple's disease were PCR positive for T whippelii on duodenal biopsies and 12 patients (11.4\%) had positive PCR results on gastric juice. ${ }^{43}$ PCR positivity in saliva has also been reported in a high proportion $(35 \%)$ of healthy individuals. ${ }^{44}$ These findings suggest that $T$ whippelii is an oral commensal and accord with its presence in soil. In an anonymous survey of blood donors we found one of 174 individuals to be PCR positive for $T$ whippelii. ${ }^{45}$ These data on background positivity in various fluids and tissues are clearly important in assessing the diagnostic importance of PCR for T whippelii.

\section{Other laboratory abnormalities in Whipple's disease}

As with other infective disorders, over $70 \%$ of patients with systemic Whipple's disease ex-

Table 3 List of antibiotics reported to be effective in the treatment of Whipple's disease

\begin{tabular}{|c|c|c|c|}
\hline Antibiotic & Ability to penetrate blood-brain barrier & $\begin{array}{l}\text { Intracellular } \\
\text { penetration }\end{array}$ & $\begin{array}{l}\text { Bactericidal/ } \\
\text { static activity }\end{array}$ \\
\hline \multicolumn{4}{|l|}{ Cephalosporins } \\
\hline Ceftriaxone & Yes, if meninges are inflamed & Poor & Bactericidal \\
\hline \multicolumn{4}{|l|}{ Cefixime } \\
\hline Chloramphenicol & Excellent, even with uninflamed meninges & Good & Bacteriostatic \\
\hline Cotrimoxazole & Good, even with uninflamed meninges & Yes & Bacteriostatic \\
\hline Azithromycin & Limited & Excellent & Bacteriostatic \\
\hline Clarithromycin & Limited & Good & Bacteriostatic \\
\hline Erythromycin & $\begin{array}{l}\text { Penetration limited even with inflamed } \\
\text { meninges }\end{array}$ & Limited & Bacteriostatic \\
\hline Penicillin & Yes, if meninges are inflamed & Poor & Bactericidal \\
\hline Streptomycin & Poor & Poor & Bactericidal \\
\hline Tetracycline & Poor & Good & Bacteriostatic \\
\hline
\end{tabular}

Bacteriocidal/static activity refers to in vitro activity of each agent against most conventional pathogens that can be cultured in the laboratory.

Table 4 Treatment of Whipple's disease: frequency of relapses according to antibiotic regimen

\begin{tabular}{|c|c|c|c|c|c|}
\hline \multirow[b]{2}{*}{ Antibiotic } & \multicolumn{4}{|l|}{ Relapses } & \multirow{2}{*}{$\begin{array}{l}\text { - Total } \\
\text { number }\end{array}$} \\
\hline & Keinath $^{47 a}$ & Fleming $^{19}$ & Feurle $e^{48}$ & Durand $^{16}$ & \\
\hline Tetracycline & $21 / 49$ & $2 / 16$ & $9 / 22$ & $5 / 28$ & $37 / 115$ \\
\hline Penicillin + Strep & $4 / 20$ & $0 / 7$ & & $0 / 7$ & $4 / 34$ \\
\hline Cotrimoxazole & $0 / 3$ & $0 / 0$ & $1 / 8$ & $0 / 12$ & $1 / 23$ \\
\hline Others & $6 / 16$ & $0 / 2$ & & $2 / 11$ & $8 / 29$ \\
\hline Total & $31 / 88$ & $2 / 25$ & $10 / 30$ & $7 / 52$ & $50 / 201$ \\
\hline
\end{tabular}

The denominator refers to number of patients treated.

Refer to individual references for data on duration of treatment.

Strep, streptomycin. hibit a non-specific acute phase response, as indicated by a raised erythrocyte sedimentation rate. ${ }^{1619}$ In patients with classic Whipple's disease affecting the gastrointestinal tract, anaemia and hypoalbuminaemia were noted in $75 \%$ and $93 \%$ of patients, respectively. ${ }^{19}$ More interestingly, Lowsky et al found Twhippelii as intra-erythrocytic inclusions in two asplenic patients on peripheral blood smears using Wright's stain. ${ }^{46}$ In this respect, $T$ whippelii is similar to other haematotropic organisms, such as species of babesia and plasmodium, and may well cause more severe disease in asplenic individuals.

\section{Management}

The optimal regimen for Whipple's disease has been largely determined by a combination of clinical experience and empiricism. The rarity of this disorder coupled with considerable difficulties in culturing $T$ whippelii have prevented randomised trials of antibiotic treatment being carried out. In managing a patient with Whipple's disease, three important questions should be considered, namely:

(1) What is the optimal antibiotic regimen?

(2) What should the duration of treatment be?

(3) How should the patient be monitored?

WHAT IS THE OPTIMAL ANTIBIOTIC REGIMEN? Beginning with Paulley's use of chloramphenicol, several antibiotics have been used successfully in the treatment of Whipple's disease (table 3). Until the 1970s, the most commonly used regimen was a combination of parenteral penicillin and streptomycin to initiate treatment followed by maintenance oral tetracycline. However, the recognition that central nervous system relapses were an important cause of mortality in patients previously treated with tetracycline, prompted the use of cotrimoxazole, which achieves effective therapeutic concentrations in CSF even in the absence of meningeal inflammation. ${ }^{47}$ The superiority of cotrimoxazole over tetracycline in preventing clinical relapses has been shown in a small partially retrospective non-randomised study. ${ }^{48}$ To date, this is the only study that has attempted to evaluate antibiotic treatment in Whipple's disease. Taken together with three other studies, the lowest frequency of relapse appears to occur in patients treated with cotrimoxazole when compared with groups treated with tetracycline and penicillin (table 4 ).

Because of the limited clinical data available, it is important to make a distinction between those patients who have neurological disease at the time of diagnosis and those who do not. In the first group it would be prudent to initiate treatment with parenteral bactericidal antibiotics with good central nervous system penetration (table 3) for a period of two weeks followed by maintenance oral cotrimoxazole. In the second group, oral treatment with cotrimoxazole is recommended on the grounds that this may be more successful in preventing neurological disease. 
WHAT SHOULD THE DURATION OF TREATMENT BE? There is no clear consensus in the literature on the duration of antibiotic treatment. Therapeutic success has been achieved with short treatment courses of three months, ${ }^{19}$ although it is possible that such patients relapse more frequently. There is some evidence that suggests an increased rate of relapse in patients treated for less than six months in comparison to those treated for 12-24 months. ${ }^{16}$ At the other end of the scale some patients have failed to respond to 64 months of continuous tetracycline. ${ }^{48}$

In view of this lack of clarity, a pragmatic compromise would be to treat all patients for a minimum period of 6-12 months with close clinical and laboratory monitoring (see below).

HOW SHOULD TREATMENT BE MONITORED?

Until the recent advent of PCR based assays for the detection of $T$ whippelii, the response to treatment was monitored using a combination of clinical and histological endpoints. The histological endpoint of eradication of PAS positive cells was not always achieved, with reports of persistent PAS positive cells in the small bowel of patients in clinical remission. ${ }^{48} 49$ In contrast, reversion of PCR positivity occurs within two to six months of the initiation of antibiotic treatment and correlates well with the clinical outcome. ${ }^{36} 3750$ Ramzan et al found that a negative post-treatment PCR was good evidence against future relapse, whereas a persistently positive PCR presaged clinical relapse. ${ }^{36}$

In view of the clear superiority of PCR over histology in monitoring treatment, patients with Whipple's disease are best followed up using PCR primarily. The selection of which tissues or fluid to perform PCR upon will depend on the initial clinical presentation. We would recommend that a combination of small bowel and peripheral blood be used in most patients as long as these tissues were positive pretreatment. In patients with neurological disease, monitoring CSF in addition to small bowel and peripheral blood is likely to be of value.

THERAPEUTIC OPTIONS IN WHIPPLE'S DISEASE UNRESPONSIVE TO ANTIBIOTICS

IFN- $\gamma$ has recently been used successfully in the treatment of a patient with a 10 year history of antibiotic resistant Whipple's disease. ${ }^{51}$ The choice of IFN- $\gamma$ as a therapeutic agent is based on the observation of defective IFN- $\gamma$ and IL-12 production in vitro by mononuclear cells from patients with Whipple's disease ${ }^{12}$ and its success in treating other intracellular infections. ${ }^{52}{ }^{53}$ Although its therapeutic success in this single case is encouraging, the authors rightly point out that this does not constitute conclusive evidence of a primary defect in IFN- $\gamma$ production in Whipple's disease.

\section{Concluding remarks}

Much progress has been made in our understanding of Whipple's disease this century. The recent identification of the putative Whipple's bacillus has fuelled advances in the use of molecular diagnostic methods, which in turn has helped uncover unusual extra-intestinal modes of clinical presentation. The use of PCR has also helped place the diagnosis and management of this disorder on a more scientific footing. It is also becoming apparent that the Whipple's bacillus is more widely prevalent than was originally thought. The development of clinical disease is likely to be determined by host factors, with the tantalising suggestion of a defective IL-12/IFN- $\gamma$ pathway in some patients.

\section{Addendum}

Since the submission of this leader, Raoult et al have successfully cultivated $T$ whippelii using a human fibroblast cell line that was injected with an aortic valve extract from a patient with Whipple's disease. ${ }^{58}$

We thank Dr Kevin Kerr for help with compiling table 3 and critical comments on the manuscript. Faye Storey's excellent secretarial support is gratefully acknowledged.

1 Whipple GH. A hitherto undescribed disease characterised anatomically by deposits of fat and fatty acids in the intestinal mesenteric lymphatic tissues. fohn Hopkins Hospital Bulletin 1907:18:382-91.

2 Paulley JW. A case of Whipple's disease (intestinal lipodystrophy). Gastroenterology 1952;22:128-33.

2a Fricker EJ, McDonald TJ. Tropheryma whippelii (images in clinical medicine). N Engl f Med 1996;335:26.

3 Chears WC, Jr, Ashworth CT. Electron microscopic study of the intestinal mucosa in Whipple's diseaseof the intestinal mucosa in Whipple's diseasedemonstration of encapsulated bacillifo

lesion. Gastroenterology 1961;41:129-38.
4 Fredricks DN, Relman DA. Sequence-based identification of microbial pathogens: a reconsideration of Koch's postulates. Clin Microbiol Rev 1996;9:18-33.

5 Wilson KH, Blitchington R, Frothingham R, et al. Phylogeny of the Whipple's disease associated bacterium. Lancet 1991;338:474-5.

6 Relman DA, Schmidt TM, MacDermott RP, et al. Identification of the uncultured bacillus of Whipple's disease. $N$ Engl f Med 1992;327:293-301.

7 Schoedon G, Goldenberger D, Forrer R, et al. Deactivation of macrophages with interleukin-4 is the key to the isolation of Tropheryma whippelii. $\mathcal{F}$ Infect Dis 1997;176:672-7.

8 Relman DA. The Whipple bacillus lives (ex vivo) [editorial]!

J Infect Dis 1997;176:752-4.
9 Dobbins WO, III. Is there an immune deficit in Whipple's Dobbins WO, III. Is there an immune
disease? Dig Dis Sci 1981;26:247-52.

10 Marth T, Roux M, von Herbay A, et al. Persistent reduction of complement receptor 3 chain expressing mononuclear blood cells and transient inhibitory serum factors in Whipple's disease. Clin Immunol Immunopathol 1994;72:217-26.

11 Bjerkness R, Odergaard S, Bjerkvig R, et al. Whipple's disease - demonstration of a persisting monocyte and macrophage dysfunction. Scand $\mathcal{F}$ Gastroenterol 1988;23:61119.

12 Marth T, Neurath M, Cuccherini BA, et al. Defects of monocyte interleukin 12 production and humoral immunity in Whipple's disease. Gastroenterology 1997;113:442-8.

13 Misbah SA, Ozols B, Franks A, et al. Whipple's disease without malabsorption: new atypical features. $Q 7 \mathrm{Med}$ 1997;90:765-72

14 Dobbins WO, III. Whipple's disease. Springfield: Charles C Thomas, 1987.

15 Maiwald M, Schuhmacher F, Ditton HJ, et al. Environmental occurrence of the Whipple's disease bacterium (Tropheryma whippelii). Appl Environ Microbiol 1998;64:760-2.

16 Durand DV, Lecomte C, Cathebras P, et al. Whipple's disease-clinical review of 52 cases. Medicine (Baltimore) disease-clinical revi

17 Weiner SR, Utsinger PD. Whipple's disease. Semin Arthritis Rheum 1986;15:157-70.

18 Maizel H, Ruffin JM, Dobbins WO, III. Whipple's disease: a review of 19 patients from one hospital and a review of the iterature since 1950. Medicine (Baltimore) 1970;49:175205.

19 Fleming JL, Weisner RH, Shorter RG. Whipple's disease: clinical, biochemical, and histopathological features and assessment of treatment in 29 patients. Mayo Clin Proc 1988;63:539-51.

20 Feurle GE, Volk B, Waldherr R. Cerebral Whipple's disease with negative jejunal histology. N Engl f Med 1979;300: 907-8.

21 Adams M, Rhyner PA, Day J, et al. Whipple's disease confined to the central nervous system. Ann Neurol 1987;21:104-8.

22 Wroe SJ, Pires M, Harding B, et al. Whipple's disease confined to the CNS presenting with multiple intracerebral mass lesions. F Neurol Neurosurg Psychiatry 1991;54:989mass. 
23 Louis ED, Lynch T, Kaufmann P, et al. Diagnostic guidelines in central nervous system Whipple's disease. guidelines in central nervo
Ann Neurol 1996;40:561-8.

24 Cho C, Lincscheer WG, Hirschkorn MA, et al. Sarcoid-like granulomas as an early manifestation of Whipple's disease. Gastroenterology 1984:87:941-7.

25 Southern JF, Moscicki RA, Magro C, et al. Lymphedema, lymphocytic myocarditis, and sarcoid-like granulomatosis: manifestations of Whipple's disease. FAMA 1989;261: 1467-70

26 Peters FPJ, Wouters RSME, Bruine AP de, et al. Cerebral relapse of sarcoid-like Whipple's disease. Clin Infect Dis 1997;24:1252-5.

27 Rouillon A, Menkes CJ, Gerster JC, et al. Sarcoid-like forms of Whipple's disease-report of 2 cases. F Rheumatol 1993; 20:1070-2.

28 Jeserich M, Ihling C, Holubarsch C. Aortic valve endocarditis with Whipple's disease [letter]. Ann Intern Med tis with Whip 1997;126:920.

29 Schneider T, Salamon-Looijen M, von Herbay A, et al. Whipple's disease with aortic regurgitation requiring aortic Whipple's disease with aortic regurgitation requir
valve replacement. Infection 1998;26:178-80.

30 Wendler D, Mendoza E, Schleiffer T, et al. Tropheryma whippelii endocarditis confirmed by polymerase chain reaction. Eur Heart f 1995;16:424-5.

31 Wright CB, Hiratzka LF, Crossland S, et al. Aortic insufficiency requiring valve replacement in Whipple's disease. Ann Thorac Surg 1978;25:466-9.

32 Gubler JGH, Kuster M, Dutly F, et al. Whipple endocarditis without overt gastrointestinal disease: report of four cases. Ann Intern Med 1999;131:112-16.

33 Raoult D. Afebrile blood culture-negative endocarditis [editorial]. Ann Intern Med 1999;131:144-6.

34 Dobbins WO, III. Whipple's disease. Springfield: Charles C Thomas, 1987.

35 Rickman LS, Freeman WR, Green WR, et al. Uveitis caused by Tropheryma whippelii (Whipple's bacillus). $N$ Engl $\mathcal{F}$ Med 1995;332:363-6.

35a Dobbins WO. The diagnosis of Whipple's disease. $N$ Engl Med 1995;332:390-2

36 Ramzan NN, Loftus E, Burgart LJ, et al. Diagnosis and monitoring of Whipple's disease by polymerase chain reacmonitoring of Whipple's disease by poly

37 Pron B, Poyart C, Abachin E, et al. Diagnosis and follow-up of Whipple's disease by amplification of the 16S r RNA gene of Tropheryma whippelii. Eur $\mathcal{F}$ Clin Microbiol Infect Dis 1999;18:62-5.

38 Marth T, Fredricks D, Strober W, et al. Limited role for PCR-based diagnosis of Whipple's disease from periphera blood mononuclear cells. Lancet 1996;348:66-7.

39 Von Herbay A, Ditton HJ, Schuhmacher F, et al. Whipple's disease: staging and monitoring by cytology and polymerase chain reaction analysis of cerebrospinal fluid Gastroenterology 1997;113:434-41.

40 Cohen L, Berthet K, Dauga C, et al. Polymerase chain reaction of cerebrospinal fluid to diagnose Whipple's disease. Lancet 1996;347:329.

41 Averbuch-Heller L, Paulson GW, Daroff R, et al. Whipple's disease mimicking progressive supranuclear palsy: the
diagnostic value of eye movement recording. 7 Neurol Neudiagnostic value of eye movement
rosurg Psychiatry 1999;66:532-5.
42 O'Duffy JD, Griffing WL, Li CY, et al. Whipple's arthritisdirect detection of Tropheryma whippelii in synovial fluid direct detection of Tropheryma whippelii in
and tissue. Arthritis Rheum 1999;42:812-17.

43 Ehrbar HU, Bauerfeind P, Dutly F, et al. PCR-positive tests for Tropheryma whippelii in patients without Whipple's disease. Lancet 1999;353:2214

44 Street S, Donoghue HD, Neild GH. Tropheryma whippelii DNA in saliva of healthy people. Lancet 1999;354:1178-9.

45 Misbah SA, Stirzaker D, Ozols B, et al. Anonymous survey of blood donors by polymerase chain reaction for Tropheryma whippelii. $Q \mathcal{F}$ Med 1999;92:61.

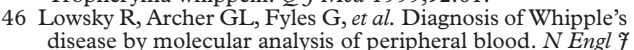
Med 1994;331:1343-6.

47 Wang EEL, Prober CG. Ventricular cerebrospinal fluid concentrations of trimethoprim-sulphamethoxazole. 7 Antimicrobial Chemotherapy 1983;11:385-9.

47a Keinath RD, Merrell DE, Vlietstra R, et al. Antibiotic treatment and relapse in Whipple's disease. Long term follow-up of 88 patients. Gastroenterology 1985;88:186773.

48 Feurle GE, Marth T. An evaluation of antimicrobial treatment for Whipple's disease-tetracycline versus imethoprim-sulphamethoxazole. Dig Dis Sci 1994;39: $1642-8$

49 Martin FF, Vilseck J, Dobbins WO, III, et al. Immunological alteration in patients with treated Whipple's disease. Gastroenterology 1972:63:6-18.

50 Muller C, Peterman D, Stain C, et al. Whipple's disease: comparison of histology with diagnosis based upon polymerase chain reaction in four consecutive cases. Gut 1997;40:425-7.

51 Schneider T, Stallmach A, Von Herbay A, et al. Treatment of refractory Whipple's disease with interferon- $\gamma$. Ann Intern Med 1998;129:875-7.

52 Holland SM, Eisenstein EM, Kuhns DB, et al. Treatment of refractory disseminated nontuberculous mycobacterial infection with interferon- $\gamma$ - a preliminary report. $N$ Engl $\mathcal{F}$ Med 1994:330:1348-55.

53 Gallin JI, Farber JM, Holland SM, et al. Interferon- $\gamma$ in the management of infectious diseases. Ann Intern Med 1995;123:216-24.

54 Marth T, Strober W. Whipple's disease [review]. Semin Gastrointest Dis 1996;7:41-8.

5 Poorman JC, Katon RM. Small bowel involvement by Mycobacterium avium complex in a patient with AIDS: endoscopic, histologic and radiographic similarities to Whipple's disease. Gastrointest Endosc 1994;40:753-9.

56 Khavari PA, Bolognia JL, Eisen R, et al. Periodic acid-Schiff positive organisms in primary cutaneous Bacillus cereus infection-case report and an investigation of periodic acid-Schiff staining properties of bacteria. Arch Dermatol 1991;127:543-6.

57 Hamrock D, Azmi FH, O’Donnell E, et al. Infection by Rhodococcus equi in a patient with AIDS: histological appearance mimicking Whipple's disease and Mycobacterium avium intracellular infection. F Clin Pathol 1999;52: 68-71.

58 Raoult D, Birg ML, La Scola B, et al. Cultivation of the bacillus of Whipple's disease. N Engl f Med 2000;342:6205. 